\title{
Quintic Trigonometric Bézier Curve with Two Shape Parameters
}

(Lengkung Bézier Trigonometri Kuintik dengan Dua Parameter Bentuk)

\author{
MisRo, M.Y*, RAMLI, A. \& ALI, J.M.
}

\begin{abstract}
The fifth degree of trigonometric Bézier curve called quintic with two shapes parameter is presented in this paper. Shape parameters provide more control on the shape of the curve compared to the ordinary Bézier curve. This technique is one of the crucial parts in constructing curves and surfaces because the presence of shape parameters will allow the curve to be more flexible without changing its control points. Furthermore, by changing the value of shape parameters, the curve still preserves its geometrical features thus makes it more convenient rather than altering the control points. But, to interpolate curves from one point to another or surface patches, we need to satisfy certain continuity constraints to ensure the smoothness not just parametrically but also geometrically.
\end{abstract}

Keywords: Bézier curve; parameterization; quintic trigonometric Bézier; shape parameter; trigonometric function

\section{ABSTRACT}

Tahap kelima lengkung Bézier trigonometri yang dipanggil kuintik dengan dua parameter bentuk dibincangkan dalam kertas ini. Parameter bentuk memberikan lebih kawalan kepada bentuk lengkung berbanding lengkung Bézier biasa. Teknik ini penting dalam membina lengkung dan permukaan kerana kehadiran parameter bentuk akan membantu lengkung menjadi lebih fleksibel tanpa mengubah titik kawalannya. Tambahan pula, dengan menukarkan nilai parameter bentuk, lengkung tersebut masih mengekalkan ciri geometri sedia ada, maka lebih mudah daripada mengubah titik kawalan. Tetapi, untuk membuat interpolasi lengkung dari satu titik ke satu titik yang lain atau permukaan tampalan, kekangan keselanjaran tertentu perlu dipenuhi untuk memastikan kelicinan bukan sahaja secara parameter tetapi juga secara geometri.

Kata kunci: Bézier trigonometri kuintik; fungsi trigonometri; lengkung Bézier; parameteran; parameter bentuk

\section{INTRODUCTION}

Rapid research in curves and surfaces contributes towards the field of Computer Aided Geometric Design (CAGD). Several inventive curves are being developed such as Bézier-like, log-aesthetic curve (Gobithaasan 2013) and spiral curve. Bézier curve is one of the typical parametric curves with a continuous curvature that is utilized in various applications including medical and engineering. Constructing two pieces of Bézier curve or piecewise method may be challenging in terms of preserving continuity and fulfilling certain shape requirements such as curvature and torsion. In order to preserve some geometrical properties, we may need to satisfy some continuity constraint between two merging curves. As a result, when two curves are merged without proper continuity, the curve of the first segment will not merge nicely with the curve at second segment at a particular joint. Thus, the continuous curvature of the curve will not be ensured.

Ahmad et al. (2014) constructed a new generalization basis called A-Bézier that has a basis space span of $\{1$, $\left.t, t^{2}, \ldots, t^{n}\right\}$ by using a systolic array. Previously, Mainar et al. (2001) constructed $\alpha$-basis of quartic Bernstein. Another approach by Chen and Wang (2003) used integral by proposed C-Bézier. Most of these functions do not enclose free form curves of a higher-order polynomial. Recently, the degree of trigonometric Bézier curve is also discussed from a lower to a higher degree such as quadratic trigonometric Bézier curve (Uzma et al. 2012), cubic trigonometric Bézier curve Han et al. (2009), quartic trigonometric Bézier curve (Dube et al. 2013; Zhu et al. 2012), quasi-quintic trigonometric Bézier curve (Uzma et al. 2013) and quintic trigonometric Bézier curve (Dube \& Bharti 2014).

Throughout this paper, we organized our work as follows. In Section 2, a new function which is quintic trigonometric Bézier curve with two shape parameter will be proposed. This new basis of quintic trigonometric Bézier curve produces a different curve compared to (Dube \& Bharti 2014). In Dube and Bharti (2014), they used 4 control points that mimics cubic trigonometric Bézier curves with a single shape parameter.

In this establishment, we utilized 6 control points with two significant shape parameters and some properties are presented. In Section 3, quintic trigonometric Bézier curve and its geometric properties are discussed. In addition to that, the usage and effects of those parameters to our newly proposed curve will be intensified. Theorems are presented 
in Section 4. In this section, the proposed curve will utilize the theorems in order to satisfy certain continuity condition. On top of that, two cases of shape parameters with similar and different values on a piece of a curve are shown.

\section{QUINTIC TRIGONOMETRIC BÉZIER BASIS FUNCTION}

Quintic trigonometric Bézier curve with two shape parameters $\alpha$ and $\beta$ is defined as:

$$
z(t)=\sum_{i=0}^{5} P_{i} f_{i}
$$

where $P_{i}$, is the control points and $f_{i}$ is the basis function for quintic trigonometric Bézier with $i=0,1,2,3,4,5$ whereas,

$$
\begin{aligned}
& f_{0}(t)=\left(1-\sin \frac{\pi t}{2}\right)^{4}\left(1-\alpha \sin \frac{\pi t}{2}\right) \\
& f_{1}(t)=\sin \frac{\pi t}{2}\left(1-\sin \frac{\pi t}{2}\right)^{3}\left(4+\alpha-\alpha \sin \frac{\pi t}{2}\right) \\
& f_{2}(t)=\left(1-\sin \frac{\pi t}{2}\right)^{2}\left(1-\cos \frac{\pi t}{2}\right)\left(8 \sin \frac{\pi t}{2}+3 \cos \frac{\pi t}{2}+9\right) \\
& f_{3}(t)=\left(1-\cos \frac{\pi t}{2}\right)^{2}\left(1-\sin \frac{\pi t}{2}\right)\left(8 \cos \frac{\pi t}{2}+3 \sin \frac{\pi t}{2}+9\right) \\
& f_{4}(t)=\cos \frac{\pi t}{2}\left(1-\cos \frac{\pi t}{2}\right)^{3}\left(4+\beta-\beta \cos \frac{\pi t}{2}\right) \\
& f_{5}(t)=\left(1-\cos \frac{\pi t}{2}\right)^{4}\left(1-\beta \cos \frac{\pi t}{2}\right),
\end{aligned}
$$

where $\alpha, \beta \in[-4,1]$ are shape parameters for the following six functions of $t$, where $t \in[0,1]$.

Figure 1 shows the quintic trigonometric Bézier basis function for two arbitrarily selected real values of $\alpha$ and $\beta$.

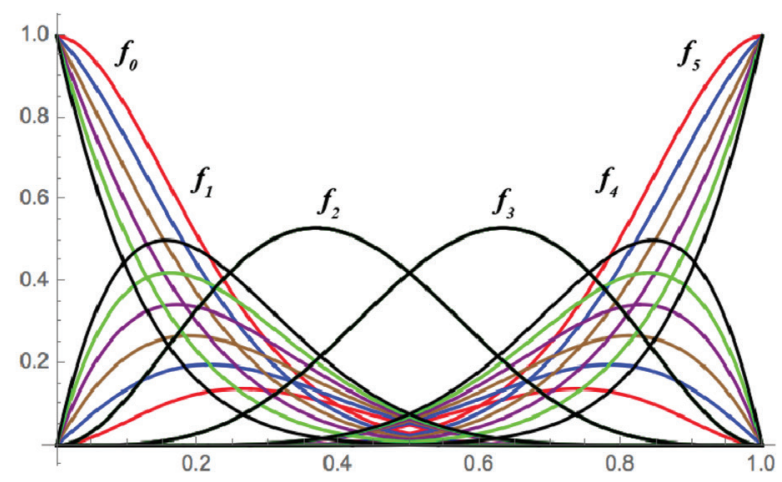

FIGURE 1. Quintic trigonometric Bézier basis function

\section{Geometric Properties}

(a) Non-negativity

$f_{i}(t) \geq 0, i=0,1,2,3,4,5$.

(b) Partition of unity

$\sum_{i=0}^{5} f_{i}(t) \equiv 1$ (c) Symmetry

$$
f_{i}(t ; \alpha, \beta)=f_{5-i}(1-t ; \alpha, \beta) \text { for } i=[0,5]
$$

Proof:

(a) For $t \in[0,1]$ and $\alpha, \beta \in[-4,1]$, then $1-\sin \frac{\pi t}{2} \geq 0$, $1-\cos \frac{\pi t}{2} \geq 0, \quad \sin \frac{\pi t}{2} \geq 0, \quad \cos \frac{\pi t}{2} \geq 0,1-\alpha \sin \frac{\pi t}{2} \geq 0$, $1-\beta \cos \frac{\pi t}{2} \geq 0,4+\alpha-\alpha \sin \frac{\pi t}{2} \geq 0,4+\beta-\beta \cos \frac{\pi t}{2} \geq 0$.

(b) $\sum_{i=0}^{5} f_{i}(t)=f_{0}(t)+f_{1}(t)+f_{2}(t)+f_{3}(t)+f_{4}(t)+f_{5}(t) \equiv 1$.

(c) $f_{0}(t ; \alpha, \beta)=\left(1-\sin \frac{\pi t}{2}\right)^{4}\left(1-\alpha \sin \frac{\pi t}{2}\right)$

$$
\begin{aligned}
& =\left(1-\cos \frac{\pi(1-t)}{2}\right)^{4}\left(1-\beta \cos \frac{\pi(1-t)}{2}\right) \\
& =f_{5}(1-t ; \beta, \alpha)
\end{aligned}
$$

\section{QUINTIC TRIGONOMETRIC BÉZIER CURVE}

Given point $P_{i}$, where $i=0,1,2,3,4,5$ in $\mathbb{R}^{2}$ or $\mathbb{R}^{3}$. Then

$$
r(t)=\sum_{i=0}^{5} P_{i} f_{i}(t) \quad t \in[0.1], \quad \alpha, \beta \in[-4,1],
$$

is called a quintic trigonometric Bézier curve with two shape parameters. Projection of the curves lies inside the convex hull for $\alpha, \beta \in[-4,1]$ are shown in Figure 2 .

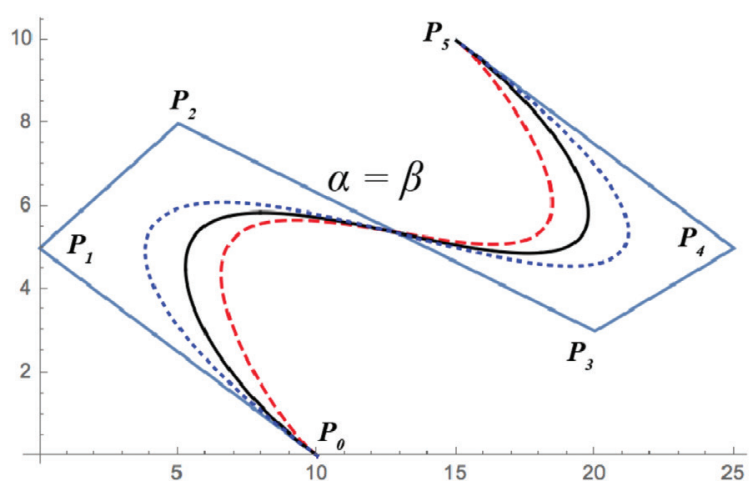

FIGURE 2. Quintic trigonometric Bézier curve with $\alpha=\beta$

Quintic trigonometric Bézier has the following properties:

1. Endpoint terminal

$$
\begin{aligned}
& r(0)=P_{0} \\
& r(1)=P_{5}
\end{aligned}
$$

$$
\begin{aligned}
& r^{\prime}(0)=\frac{-\pi}{2}\left(P_{0}-P_{1}\right)(4+\alpha) \\
& r^{\prime}(1)=\frac{-\pi}{2}\left(P_{4}-P_{5}\right)(4+\beta) .
\end{aligned}
$$




$$
\begin{aligned}
& r^{\prime \prime}(0)=\pi^{2}\left(3 P_{2}-2 P_{1}(3+\alpha)+P_{0}(3+2 \alpha)\right) \\
& r^{\prime \prime}(1)=\pi^{2}\left(3 P_{3}-2 P_{4}(3+\beta)+P_{5}(3+2 \beta)\right) .
\end{aligned}
$$

Figure 3 shows the behavior of the quintic trigonometric Bézier curve when the value of shape parameter $\alpha$ is fixed and $\beta$ is varied.



FIGURE 3. Quintic trigonometric curve with $\alpha=-3$ and $\beta=-3$ (dotted blue $), 0$ (black), 1(dashed red $)$

2. Convex hull

The entire trigonometric Bézier curve segment must lie inside its control point polygon spanned by $P_{0}, P_{1}$, $P_{2}, P_{3}, P_{4}, P_{5}$

3. Symmetry

$\left\{P_{0}, P_{1}, P_{2}, P_{3}, P_{4}, P_{5}\right\}$ and $\left\{P_{5}, P_{4}, P_{3}, P_{2}, P_{1}, P_{0}\right\}$ define the same trigonometric Bézier curve in different parameterizations, i.e.,

$r\left(t ; \alpha, \beta: P_{0}, P_{1}, P_{2}, P_{3}, P_{4}, P_{5}\right)$

$=r\left(1-t ; \alpha, \beta: P_{5}, P_{4}, P_{3}, P_{2}, P_{1}, P_{0}\right)$

where $0 \leq t \leq 1,-4 \leq \alpha, \beta \leq 1$

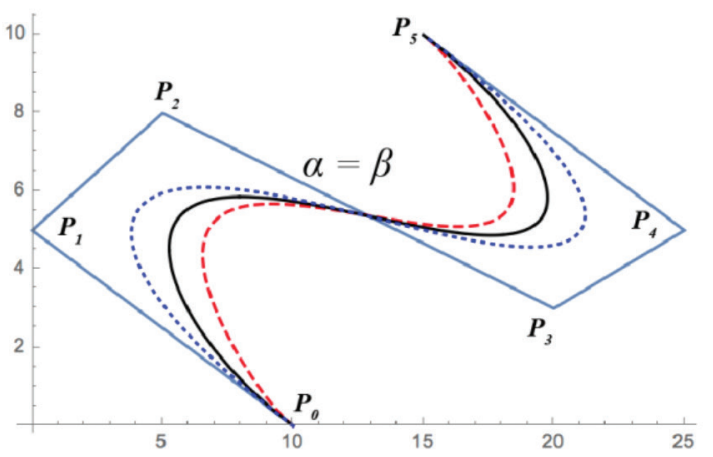

4. Geometric invariance

$$
\begin{aligned}
& r\left(t ; \alpha, \beta: P_{0}+y, P_{1}+y, P_{2}+y, P_{3}+y, P_{4}+y, P_{5}+y\right) \\
& =r\left(t ; \alpha, \beta: P_{0}, P_{1}, P_{2}, P_{3}, P_{4}, P_{5}\right)+y
\end{aligned}
$$

$$
\begin{aligned}
& r\left(t ; \alpha, \beta: P_{0} * m, P_{1} * m, P_{2} * m, P_{3} * m, P_{4} * m, P_{5} * m\right) \\
& =r\left(t ; \alpha, \beta: P_{0}, P_{1}, P_{2}, P_{3}, P_{4}, P_{5}\right) * m
\end{aligned}
$$

where $0 \leq t \leq 1,-4 \leq \alpha, \beta \leq 1$ where is an arbitrary vector in $\mathbb{R}^{2}$ or $\mathbb{R}^{3} . m$ is an arbitrary $d x d$ matrix where $d=5$ or 6 . We can see the effect of shape parameter if we let $\beta$ to be fixed like in Figure 4.

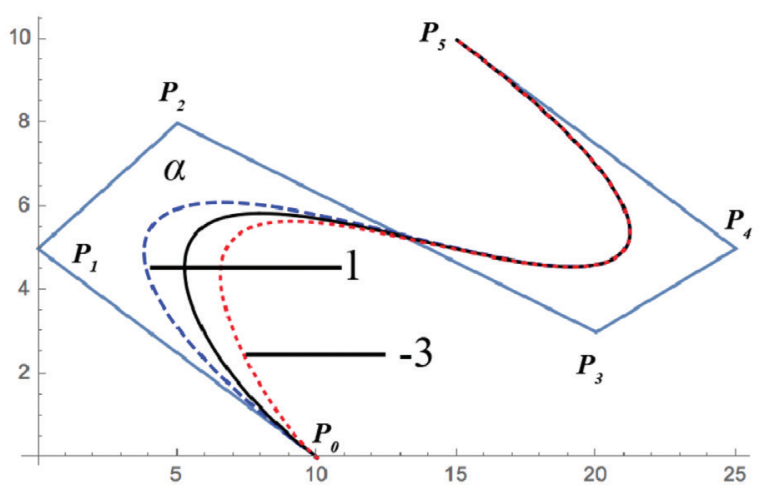

FIGURE 4. Quintic trigonometric Bézier curve with $\alpha=-3$ (dotted red), 0 (black), 1(blue) and $\beta=1$

\section{CURVATURE DISTRIBUTION OF QUINTIC TRIGONOMETRIC BÉZIER CURVE}

Curvature distribution for Figure 5 shows that the curvature profile inherits symmetrical form when we used the same value of shape parameter. When one of the variables of shape parameter either $\alpha$ or $\beta$ are fixed, it will still retain the pattern of the curvature, but the value of the amplitude of the curvature may increase or decrease as in Figures 6 and 7 .

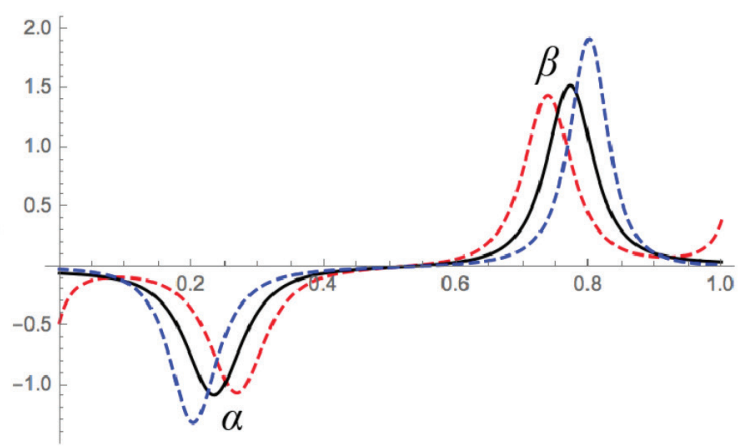

FIGURE 5. A curve with $\alpha=\beta$ (left) and its curvature distribution (right) 

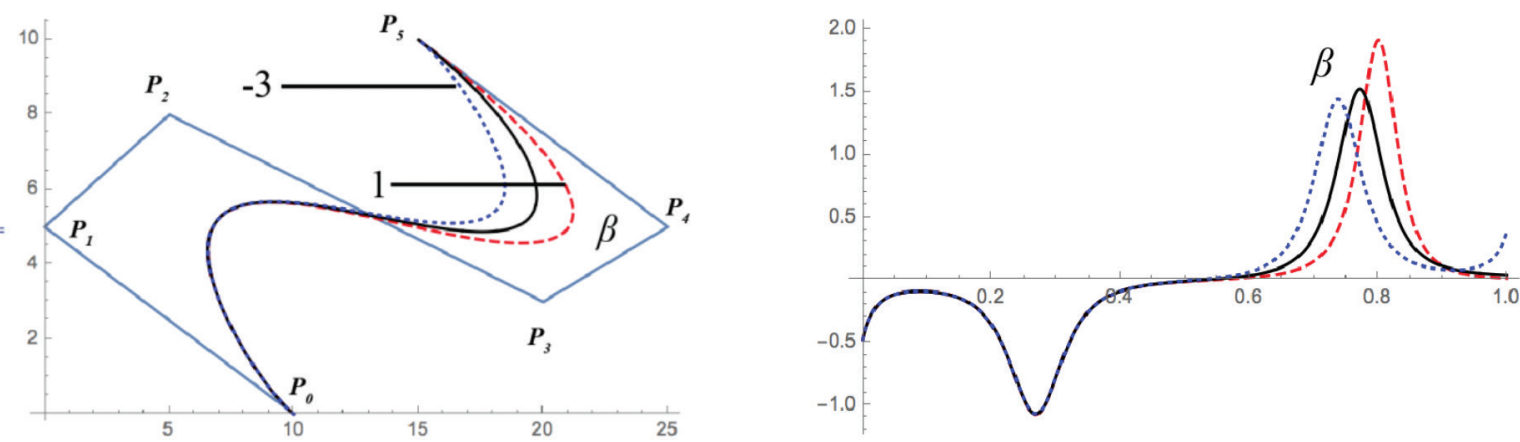

FIGURE 6. A curve with fixed $\alpha$ (left) and its curvature distribution (right)
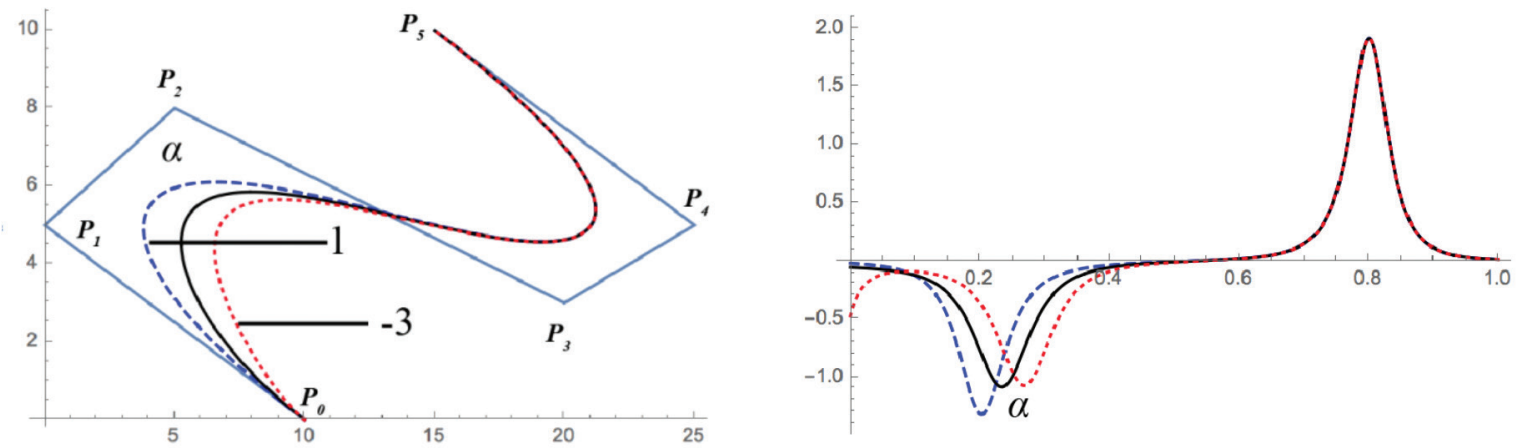

FIGURE 7. A curve with fixed $\beta$ (left) and its curvature distribution (right)

Shape control of quintic trigonometric Bézier curve makes the construction of the curve much easier and flexible. Discussion and advantages will be presented in the next section.

\section{SHAPE CONTROL OF THE QUINTIC TRIGONOMETRIC BÉZIER CURVE}

For $t \in[0,1]$ where we can write (2) as follows:

$$
\begin{aligned}
& r(t)=\sum_{i=0}^{5} P_{i} f_{i}(t)=P_{0} f_{0}(t)+P_{1} f_{1}(t)+P_{2} f_{2}(t)+P_{3} f_{3}(t) \\
& +P_{4} f_{4}(t) P_{5} f_{5}(t) .
\end{aligned}
$$

Shape parameter $\alpha$ will only affect curve on the control point of $P_{2}-P_{1}$ and $P_{1}-P_{0}$, where $\beta$ affect $P_{5}-P_{4}$ and $P_{4}-P_{3}$, respectively. In fact, from Figure 1 , we can also predict the following behavior of the curves.

As $\alpha$ increases, the curve moves in the direction of the edge $P_{2}-P_{1}$ and $P_{1}-P_{0}$, and as $\beta$ increases, the curve moves in the direction of the edge $P_{5}-P_{4}$ and $P_{4}-P_{3}$. While the shape parameter $\alpha=\beta$, the curve moves in the direction of; or, the opposite direction to the edge $P_{4}-$ $P_{3}$ and $P_{3}-P_{2}$ depending on the values of the parameter itself. This nature is called as geometric effect. For close curve the changing effect of shape parameter we can see in Figure 8.

\section{COMPOSITE TWO QUINTIC TRIGONOMETRIC BÉZIER CURVE}

Two curves can be connected by a few acceptable fashions. Connections between two curves are notable via point, tangential and positional. A curve that joined at a point is called $C^{0}$, linked at positional is named $C^{1}$ and the one connected by tangency is $C^{2}$.

In all cases, we would need to satisfy some conditions in order to achieve $C^{2}$ continuity. Strictly speaking, the presence of shape parameters does not just act as a local control for Bézier curve. These parameters will establish the flexibility of the curve. This setup may help the designer to avoid changing the control point and still be able to adjust their desired curve without the need to change control point.

Theorem 1: Let $r_{1}(t)$ and $r_{2}(t)$ be two quintic trigonometric Bézier curves. The two curves are joined by $C^{1}$ continuity at the linked point if:

$$
P_{5}\left(8+\alpha_{2}+\beta_{1}\right)-P_{4}\left(4+\beta_{1}\right)=Q_{1}\left(4+\alpha_{2}\right) \text {. }
$$

Proof. Let two quintic trigonometric Bézier curves such as

$$
r_{1}(t)=\sum_{i=0}^{5} P_{i} f_{i}(t), \quad r_{2}(t)=\sum_{i=0}^{5} Q_{i} f_{i}(t),
$$



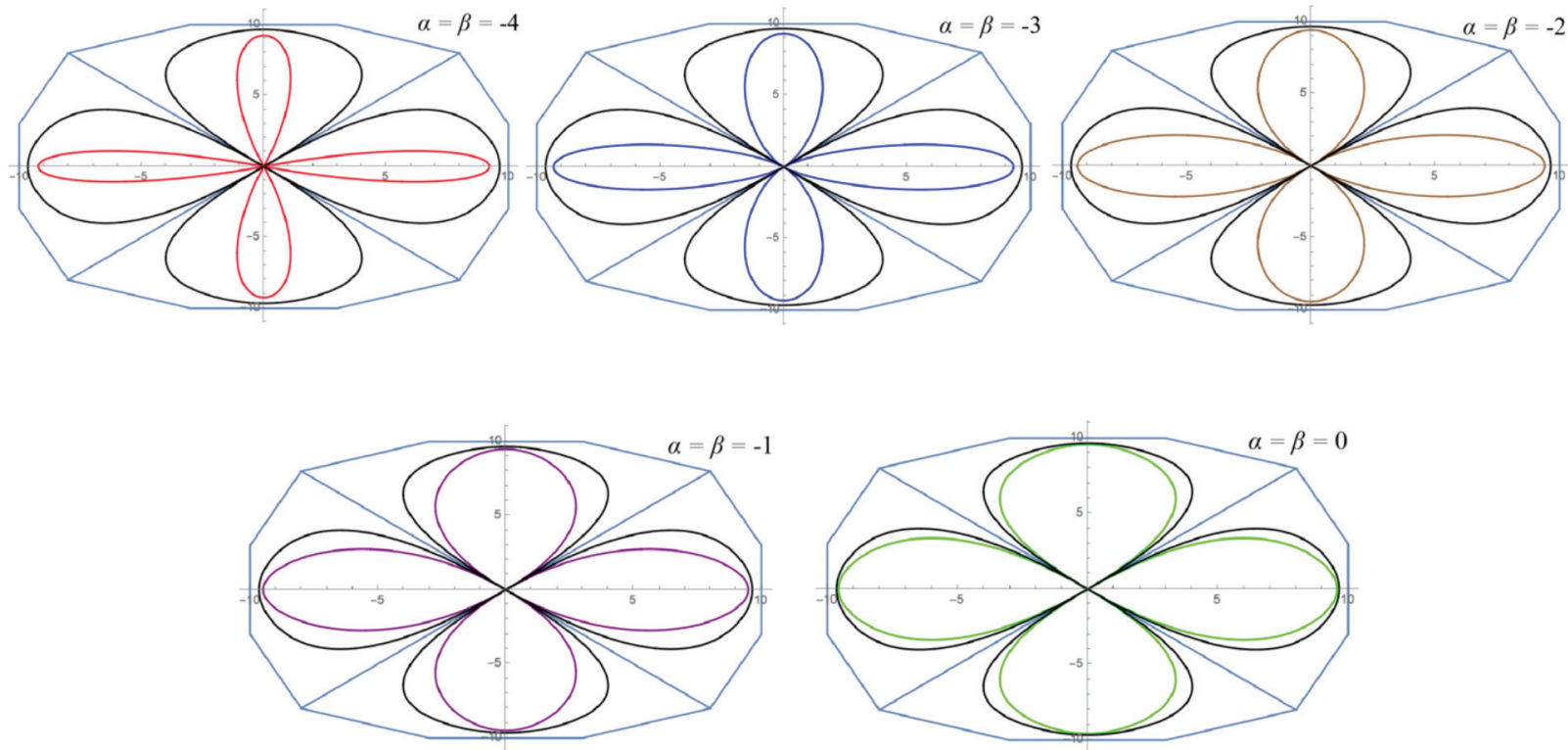

FIGURE 8. Quintic trigonometric Bézier curve on close curve for $\alpha=\beta=-4,-3,-2,-1,0$

where $P_{i}, Q_{i}$ are control point for $i=0,1,2,3,4,5$ with $\alpha_{1}, \beta_{1}$ as shape parameters for $P_{i}$, and $\alpha_{2}, \beta_{2}$ as shape parameters for $Q_{i} \cdot-4 \leq \alpha_{1}, \beta_{1}, \alpha_{2}, \beta_{2} \leq 1$.

$$
\begin{aligned}
& r_{1}(1)=\lambda r_{2}(0) \\
& r_{1}{ }^{\prime}(1)=\lambda r_{2}{ }^{\prime}(0)
\end{aligned}
$$

By substituting end-point terminal equation (6) and (7) we will obtained,

$$
\begin{aligned}
& P_{5}=\lambda Q_{0} \\
& \left(P_{4}-P_{5}\right)\left(4+\beta_{1}\right)=\lambda\left(Q_{0}-Q_{1}\right)\left(4+\alpha_{2}\right) .
\end{aligned}
$$

Rearrange the terms we have

$$
P_{5}\left(8+\alpha_{2}+\beta_{1}\right)-P_{4}\left(4+\beta_{1}\right)=\lambda Q_{1}\left(4+\alpha_{2}\right)
$$

by assuming $\lambda=1$.

Case 1. Value of shape parameter $\alpha_{i}$ equals to $\beta_{i}$ for each curve segments

Theorem 2: Let $r_{1}(t)$ and $r_{2}(t)$ be two quintic trigonometric Bézier curves. The two curves of the same pair of shape parameters are joined by $C^{2}$ continuity if they are $C^{0}, C^{1}$ and

$$
\begin{aligned}
& 3 P_{3}(4+\alpha)-2\left(P_{4}-P_{5}\right)(24+7 \beta+\alpha(7+2 \beta)) \\
& =3 Q_{2}(4+\alpha) .
\end{aligned}
$$

Proof. Two curves are joined by $C^{2}$ continuity if

$$
r_{1}^{\prime \prime}(1)=r_{2}^{\prime \prime}(0)
$$

The values of derivatives from (8) are plugged into the previous equation such as

$$
\begin{aligned}
& 3 P_{3}-2 P_{4}\left(3+\beta_{1}\right)+P_{5}\left(3+2 \beta_{1}\right)=3 Q_{2}-2 Q_{1}\left(3+\alpha_{2}\right) \\
& +Q_{0}\left(3+2 \alpha_{2}\right) .
\end{aligned}
$$

Therefore,

$$
P_{5}\left(8+\alpha_{2}+\beta_{1}\right)-P_{4}\left(4+\beta_{1}\right)=Q_{1}\left(4+\alpha_{2}\right) .
$$

By assuming $\alpha_{1}=\alpha_{2}=\alpha, \beta_{1}=\beta_{2}=\beta$. We will then obtained

$$
\begin{aligned}
& 3 P_{3}(4+\alpha)-2\left(P_{4}-P_{5}\right)(24+7 \beta+\alpha(7+2 \beta)) \\
& =3 Q_{2}(4+\alpha) .
\end{aligned}
$$

Case 2. Value of shape parameter $\alpha_{i}$ is not equal to $\beta_{i}$ for each curve but $\beta_{i}$ of the first curve equal to $\alpha_{i+1}$ for second curve

Theorem 3: Let $r_{1}(t)$ and $r_{2}(t)$ be two quintic trigonometric Bézier curves. The two curves of different pair of shape parameters are joined by $C^{2}$ continuity if $\beta_{1}=\alpha_{2}$ and they are $C^{0}, C^{1}$ and

$$
\begin{aligned}
& 3 P_{3}\left(4+\alpha_{2}\right)-2\left(P_{4}-P_{5}\right)\left(24+7 \beta_{1}+\alpha_{2}\left(7+2 \beta_{1}\right)\right) \\
& =3 Q_{2}\left(4+\alpha_{2}\right) .
\end{aligned}
$$

where $\alpha_{1}, \beta_{1}$ belongs to shape parameters of the first curve and $\alpha_{2}, \beta_{2}$ belongs to shape parameters of the second curve.

Proof. Two curves are joined by $C^{2}$ continuity if

$$
r_{1}^{\prime \prime}(1)=r_{2}^{\prime \prime}(0)
$$


The values of derivatives from (8) are plugged into the previous equation

$$
\begin{aligned}
& 3 P_{3}-2 P_{4}\left(3+\beta_{1}\right)+P_{5}\left(3+2 \beta_{1}\right)=3 Q_{2}-2 Q_{1}\left(3+\alpha_{2}\right) \\
& +Q_{0}\left(3+2 \alpha_{2}\right) .
\end{aligned}
$$

Therefore $P_{5}\left(8+\alpha_{2}+\beta_{1}\right)-P_{4}\left(4+\beta_{1}\right)=Q_{1}\left(4+\alpha_{2}\right)$. We obtained

$$
\begin{aligned}
& 3 P_{3}\left(4+\alpha_{2}\right)-2\left(P_{4}-P_{5}\right)\left(24+7 \beta_{1}+\alpha_{2}\left(7+2 \beta_{1}\right)\right) \\
& =3 Q_{2}\left(4+\alpha_{2}\right) .
\end{aligned}
$$

Figure 9 shows a composite curve made up by the two curves. Blue curve was generated using the same pair of shape parameter while the red curve was generated using different pairs of shape parameter. The second curve in black is generated using the same pair of shape parameter. With a closer look, both blue and red curves are joined nicely at $P_{5}$.

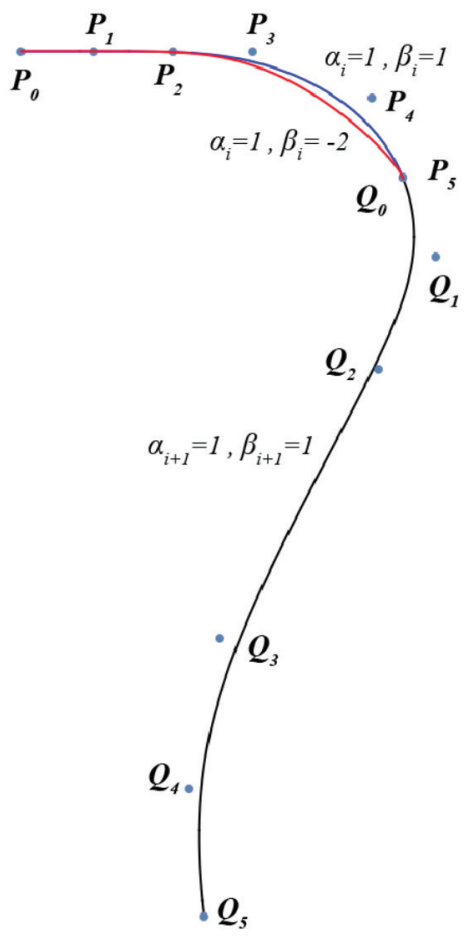

FIGURE 9. Composite two segments of Quintic Trigonometric Bézier curves

The best curve will always preserve not just parametrically but also curvature continuity. By visual observation, one cannot identify which curve preserves curvature continuity. To verify this, curvature value must be the same at the end of the first curve and the beginning of the second curve.
Curvature $\kappa(t)$ of the curve in (Hoschek et al. 1993) is defined as:

$$
\kappa(t)=\frac{r^{\prime}(t) \times r^{\prime \prime}(t)}{\left\|r^{\prime}(t)\right\|^{3}}
$$

By using control points in (27) and (28):

$$
\begin{array}{ll}
P_{0}=\left(\frac{19100}{33}, \frac{62800}{33}\right) & P_{1}=\left(\frac{20000}{33}, \frac{62800}{33}\right) \\
P_{2}=\left(\frac{7000}{11}, \frac{62800}{33}\right) & P_{3}=\left(\frac{2000}{3}, \frac{62800}{33}\right) . \\
P_{4}=\left(\frac{23500}{33}, \frac{62200}{33}\right) & P_{5}=\left(\frac{23900}{33}, \frac{20400}{11}\right) \\
Q_{0}=\left(\frac{23900}{33}, \frac{20400}{11}\right) & Q_{1}=\left(\frac{8100}{11}, \frac{60200}{33}\right) \\
Q_{2}=\left(\frac{23600}{33}, \frac{19600}{11}\right) & Q_{3}=\left(\frac{7200}{11}, \frac{55400}{33}\right) . \\
Q_{4}=\left(\frac{21200}{33}, \frac{53500}{33}\right) & Q_{5}=\left(\frac{21400}{33}, \frac{17300}{11}\right)
\end{array}
$$

The curvature, $\kappa$ values are shown in Table 1 for the first curve that consists of the blue and red curves with respect to $t$.

TABLE 1. Curvature value comparison for blue and red curve

\begin{tabular}{ccc}
\hline$t$ & $\begin{array}{c}\text { Curvature, } \kappa \\
\text { (Blue Curve) }\end{array}$ & $\begin{array}{c}\text { Curvature, } \kappa \\
\text { (Red Curve) }\end{array}$ \\
\hline $\mathbf{0}$ & 0 & 0 \\
$\mathbf{0 . 1}$ & -0.000014 & -0.000014 \\
$\mathbf{0 . 2}$ & -0.000303 & -0.000337 \\
$\mathbf{0 . 3}$ & -0.001619 & -0.002003 \\
$\mathbf{0 . 4}$ & -0.004168 & -0.005720 \\
$\mathbf{0 . 5}$ & -0.006907 & -0.009761 \\
$\mathbf{0 . 6}$ & -0.008814 & -0.010868 \\
$\mathbf{0 . 7}$ & -0.010028 & -0.008787 \\
$\mathbf{0 . 8}$ & -0.011720 & -0.006810 \\
$\mathbf{0 . 9}$ & -0.014587 & -0.009316 \\
$\mathbf{1 . 0}$ & $\mathbf{- 0 . 0 1 5 9 7 5}$ & $\mathbf{- 0 . 0 9 9 8 4 3}$ \\
\hline
\end{tabular}

Blue and red curves provides the same curvature, $\kappa$ value at the start which is zero. When $t=1$, both curves give different numerical values.

Curvature, $\kappa$ value for the black curve are listed in Table 2.

With the information shown in Tables 1 and 2, it can be deduced that the curve preserves curvature continuity from one curve to another if $\beta_{i}=\alpha_{i+1}$ for $\alpha_{i}$ that is not equal to $\beta_{i}$ for each of the curve.

\section{CONCLUSION}

In this paper, we introduced quintic trigonometric Bézier curve with two shape parameter. This new type of basis 
TABLE 2. Curvature value for second curve

\begin{tabular}{cc}
\hline$t$ & Curvature, $\kappa$ (Black Curve) \\
\hline $\mathbf{0}$ & $\mathbf{- 0 . 0 1 5 9 7 5}$ \\
$\mathbf{0 . 1}$ & -0.016542 \\
$\mathbf{0 . 2}$ & -0.009397 \\
$\mathbf{0 . 3}$ & -0.002886 \\
$\mathbf{0 . 4}$ & -0.000369 \\
$\mathbf{0 . 5}$ & 0.000737 \\
$\mathbf{0 . 6}$ & 0.001956 \\
$\mathbf{0 . 7}$ & 0.003983 \\
$\mathbf{0 . 8}$ & 0.005692 \\
$\mathbf{0 . 9}$ & 0.004781 \\
$\mathbf{1 . 0}$ & 0.003854 \\
\hline
\end{tabular}

inherits most of the geometric properties of classical Quintic Bézier curve. Parameterization of the curve can be easily done by the presence of two shape parameters, where the shape of the curve can be easily altered without changing its control point. Two shape parameters give more options for designers or engineers to maintain onesided shape while changing the other shape of the curve. A higher degree of trigonometric Bézier curve was presented in this paper with composition of two curves that fulfilled $C^{2}$ Hermite conditions. This work can be extended to shape preserving curves, designing routes or highways (Misro et al. 2015, 2017) where it will benefit from curvature continuity. Furthermore, it can be used to construct surface patches or tensor product surface.

\section{ACKNOWLEDGEMENTS}

The authors are very grateful to the anonymous referees for their valuable suggestions. This work was supported by Universiti Sains Malaysia and partially by USM FRGS 304/PMATHS/6711433.

\section{REFERENCES}

Ahmad, A., Amat, A.H. \& Ali, J.M. 2014. A generalization of Bézier-like curve. EDUCATUM- Journal of Science, Mathematics and Technology 1(2): 56-58.

Chen, Q. \& Wang, G. 2003. A class of Bézier-like curves. Computer Aided Geometric Design 20(1): 29-39.
Dube, M. \& Yadav, B. 2014. The quintic trigonometric Bézier curve with single shape parameter. International Journal Scientific and Research Publications 4(3): 2250-3153.

Dube, M.\& Sharma, R. 2013. Quartic trigonometric Bézier curve with a shape parameter. International Journal of Mathematics and Computer Applications Research 3(3): 89-96.

Gobithaasan, R.U., Karpagavalli, R. \& Miura, K.T. 2013. Shape analysis of generalized log-aesthetic curves. International Journal of Mathematical Analysis 7(33-36): 1751-1759.

Han, X.A., Ma, Y. \& Huang, X. 2009. The cubic trigonometric Bézier curve with two shape parameters. Applied Mathematics Letters 22(2): 226-231.

Hoschek, J., Lasser, D. \& Schumaker, L.L. 1993. Fundamentals of Computer Aided Geometric Design. AK Peters, Ltd.

Mainar, E., Peña, J.M. \& Sánchez-Reyes, J. 2001. Shape preserving alternatives to the rational Bézier model. Computer Aided Geometric Design 18(1): 37-60.

Misro, M.Y., Ramli, A. \& Ali, J.M. 2015. Approximating maximum speed on road from curvature information of Bézier curve. International Journal of Mathematical, Computational, Physical, Electrical and Computer Engineering 9(12): 705-712.

Misro, M.Y., Ramli, A. \& Ali, J.M. 2017. S-shaped and C-shaped transition curve using cubic trigonometric Bézier. Proceedings of 24th Malaysian National Symposium of Mathematical Sciences (SKSM24). AIP Publishing. In Press.

Uzma, B., Abbas, M., Awang, M.N.H. \& Ali, J.M. 2013. A class of quasi-quintic trigonometric Bézier curve with two shape parameters. ScienceAsia 39: 11-15.

Uzma, B., Abbas, M., Awang, M.N.H. \& Ali, J.M. 2012. The quadratic trigonometric Bézier curve with single shape parameter. Journal of Basic and Applied Scientific Research 2(3): 2541-2546.

Zhu, Y., Han, X. \& Han, J. 2012. Quartic trigonometric Bézier curves and shape preserving interpolation curves. Journal of Computational Information Systems 8(2): 905-914.

School of Mathematical Sciences

Universiti Sains Malaysia

11800 Penang, Pulau Pinang

Malaysia

*Corresponding author; email: redorange_91@yahoo.com

Received: 22 January 2016

Accepted: 1 November 2016 